\title{
A Review on Common Anthelmintics in Childhood
}

\author{
Edwin Dias ${ }^{1 *}$ and Anusha Dias ${ }^{2}$ \\ ${ }^{1}$ Professor and HOD Department of pediatrics Srinivas Medical College \& Research Centre, India \\ ${ }^{2}$ Ladyhill clinic, India
}

*Corresponding author: Edwin Dias, Professor and HOD Department of pediatrics Srinivas Medical College \& Research Centre, Adjunct Professor Srinivas University Mukka, Mangalore, India.
Received Date: March 02, 2020

Published Date: March 18, 2020

\begin{abstract}
Anthelmintics are medications that are used to treat worm-infested diseases. This comprises both flat worms e.g., flukes and tapeworms and round worms, i.e., nematodes. They are of big significance for human and veterinary medicine. Most diseases caused by helminths are chronic, debilitating in nature, they undoubtedly cause additional morbidity, higher economic and social hardship among humans and animals than the other parasites. As of late the use of anthelmintics produces lethality in people. Subsequently the advancement and revelation of new substances going about as anthelmintics are being inferred through plants which are believed to be the best inventory of bioactive substances. Anthelmintics are those medications that are utilized to oust the worms that are parasitic in nature by either stunning them or by executing them. They are furthermore called as vermifuges or vermicides. The Anthelmintics drug treatment ought to be utilized in chemotherapy programs in those areas wherever clinical help is dispersed and wherever drugs are very much endured in people.
\end{abstract}

\section{Introduction}

Anthelmintics are drugs that are utilized to treat parasitic pervasions. This involves both flat worms, e.g., flukes and tapeworms and round worms, i.e., nematodes. They are fundamental for human medication and for veterinary prescription [1]. Most maladies brought about by helminths are incessant, depleting in nature, they in all probability cause extra bleakness, higher financial and social hardship among people and creatures than different parasites. It has been said that regarding half of the total populace experiences Helminthiasis and the number is rising step by step. It isn't just constrained to tropical and subtropical nations but at the same time is to endemic in numerous districts in light of poor sanitation, poor family cleanliness, hunger and swarmed living condition [2]. Potent anthelmintics are accessible today and treatment is every now and again done by utilizing various kinds of medications. Because of the significant expenses of present day anthelmintics, successful authority over the parasites is restricted all through. Now and again, widespread utilization of low quality anthelmintics are utilized for the advancement of resistance and subsequently causes decrease use of anthelmintics [3].

\section{Anthelmintic Drugs}

Helminths diseases are the most pervasive contaminations in humankind which influences countless the total populace. In the treatment of worm-plagued infections, the anthelmintic medications are utilized regularly. The utilization of anthelmintics is said to create poisonous quality in people. Henceforth the advancement and revelation of new substances that are being gotten from plants which are viewed as the best wellspring of bioactive substances are known to show the impacts of anthelmintics. Different plants were utilized in venereal maladies, to advance mending of wounds, swellings, abscesses, ailment and treating torment in lower furthest points, skin infections, leucorrhoea, looseness of the bowels, dysuria and fever [4,5]. Anthelmintics are those medications that are utilized to unstick the worms that are parasitic in nature by either shocking them or by killing them. They are moreover called 
as vermifuges or vermicides. Regular anthelmintic incorporates the accompanying rundown of parts:

Tobacco, Walnut, Clove, Garlic, pineapple, Soya and different vegetables, Honey, water and vinegar are blended in with warm water go about as vermifuges.

\section{Helminths Infections}

\section{Ascariasis}

Ascaris lumbricoides, being notable as round worm, is the biggest and exceptionally common human nematodes. The assortment of ailment happens in ascariasis, beginning from those of larva to grown-up worms.

During the larval period of ascariasis when the larva is in the lungs, kids produces indications of bronchitis or pneumonitis. 5 to 6 days in the wake of ingesting infective eggs, patients may build up a fever $99^{\circ}-105^{\circ} \mathrm{F}$ with chills, dyspnoea, paroxysmal coughing and hemoptysis, which may exacerbate during the next week.

\section{Ancylostomiasis}

Ancylostomiasis is a hookworm ailment brought about by disease with Ancylostoma hookworms. Ancylostomiasis is caused when hookworms, present in huge numbers, produce an iron lack anaemia by sucking blood from the host's intestinal walls. It causes nearby extreme itching and a red serpiginous injury.

\section{Enterobius}

Enterobius vermicularis (pinworm) invasion is very normal, particularly in kids. Frequently contamination is symptomless, yet more regularly there is perianal tingling because of the grown-up females, which lay the eggs in the perianal area. Reinfection and individual to-individual transmission are normal. During colonoscopy, the grown-up female worms can be found in the cecum, climbing colon, or distal ileum as white worms of 8-13 mm long.

\section{Strongyloidiasis}

People get S.stercoralis disease by entrance of skin or mucous films by the infective filariform larvae; this contamination is generally a consequence of contact with tainted soil. Side effects incorporate stomach torment and looseness of the bowels, cough, wheezing or pruritis.

\section{Trichuriasis}

Trichuriasis is brought about by different types of Trichuris, nematode parasites otherwise called whipworms. Whipworms are regular in the intestinal tracts of mammals. Diseases are frequently asymptomatic; anyway, may create looseness of the bowels, and progressively genuine impacts, including diarrhea, bleeding of intestine and anaemia.

\section{Filariasis}

Filariasis is a parasitic malady brought about by a disease with roundworms of the Filarioidea type. These are spread by blood-feeding creepy insects, for example, dark flies and mosquitoes. The most staggering side effect of lymphatic filariasis is elephantiasis - edema with thickening of the skin and basic tissues.

\section{Taeniasis}

This disease is brought about by Taenia solium (the pork tapeworm) and T. saginata (the beef tapeworm). Larvae are bound to cause illness than the grown-up tapeworms. Side effects, assuming any, are normally restricted to unthriftiness, discomfort, fractiousness, diminished hunger and mild loose bowels.

\section{Cysticercosis}

Contamination with the larval type of Taenia solium, T. saginata, T. crassiceps T. ovis, T. taeniaeformis or T. hydatigena is called cysticercosis. The larvae of these living beings are called cysticerci. The clinical signs are generally restricted to transient fever, languor and gentle neurologic signs, for example, a slight head tilt. Progressively serious illness, including intense meningoencephalitis, seizures and demise can happen.

\section{Hydatid disease}

Hydatid disease is a parasitic sickness brought about by echinococcus. Children with essential hydatid cyst of the spleen gave a hauling sensation as well as torment in the left hypochondrium.

\section{Classification According to Parasite Worms}

- $\quad$ For ROUNDWORM (Ascaris lumbricoides)

Mebendazole, Albendazole, Pyrantel P. Piperazine, Levamisole, Ivermectin

- For HOOKWORM (Ancylostoma duodenale, Necator americanus)

Mebendazole, Albendazole, Pyrantel. P, Levamisole

- $\quad$ For THREADWORM (Enterobius vermicularis)

Mebendazole, Albendazole, Pyrantel P, Piperazine

- $\quad$ For Strongyloides stercoralis

Ivermectin, Albendazole

- $\quad$ For WHIPWORM (Trichuris trichiura)

Mebendazole, Albendazole

- $\quad$ For Filariasis (Wuchereria bancrofti, Brugia malayi)

Diethylcarbamazine, Ivermectin, Albendazole

- $\quad$ For TAPEWORM (Taenia solium, T.saginata, Hymenolepis nana)

Praziquantel, Niclosamide, Albendazole

- $\quad$ For Hydatid disease (Echinococcus granulosus, E.multilocularis)

Albendazole, Mebendazole 


\section{Pharmacology of Drugs Based on Similar Chemical Structure and Mode of Action}

\section{Piperazine}

It is the most noticeable and quickly utilized medication for the fix of parasitic disease. Piperazine was first devoured as an anthelmintic in 1950s. It is as yet the dynamic constituent as over the counter medication and is utilized in the solutions for string worm disease in youngsters. Its method of activity has been considered in Ascaris. In Ascaris it goes about as a feeble GABA-mimetic agent by causing hyperpolarization of nerve endings and in this manner will cause a flabby or reversible loss of motion of body wall muscle.

Pediatric Dose:

- $\quad$ Round worms: $75 \mathrm{mg} / \mathrm{kg}$ of body weight for 2 consecutive days by mouth

- Pinworms: $65 \mathrm{mg} / \mathrm{kg}$ of body weight daily orally for seven consecutive days

\section{Benzimidazole}

The first thiabendazole was known to be found in 1961 and it is a broad spectrum anthelmintics. There are different investigations on benzimidazole compounds which indicated various distinctive biochemical impacts. The anthelmintic adequacy of benzimidazoles is because of the capacity of trading off the cytoskeleton through a cooperation with $\beta$-tubulin factor [6]. The sub-atomic premise of benzimidazole particle opposition has been analyzed in the parasitic nematodes. The benzimidazole atom demonstrated obstruction in various nematodes like Haemonchus contortus which is related with the nearness of explicit alleles of $\beta$-tubulin in the medication [7]. The $\beta$-tubulin isoform could profit the opposition for the medication which was tried through analyses however this demonstrated the reaction of C.elegans freaks of benzimidazole can be saved by communicating the $\mathrm{H}$. contortus alleles of $\beta$-tubulin from benzimidazole through which separation was done [8].

\section{Albendazole}

Pediatric Dose:

- $\quad$ Neurocysticercosis (Taenia Solium Tapeworm)

$>60 \mathrm{~kg}$ : 400 mg BID x 8-30 day

- $\quad$-Hydatid (Echinococcus Tapeworm)

>60 kg: 400 mg PO BID x 28 days, THEN 14 drug-free days x 3 cycles

- Ancylostoma, Ascariasis, Hookworm, Trichostrongylus 400 mg P0 x1 day

- $\quad$ Capillariasis

400 mg P0 qDay x10 days

- $\quad$ Larva Migrans, Cutaneous \& Trichuriasis
400 P0 qDay x3 days

\section{Mebendazole}

Pediatric Dose:

- $\quad$ Pinworm (Enterobius vermicularis)

Emverm, $\geq 2$ years: $100 \mathrm{mg} \mathrm{PO}$ as a single dose

If cure is not achieved $3 \mathrm{wk}$ after treatment, a second course of treatment is advised

- $\quad$ Roundworm (Ascaris lumbricoides)

Emverm $\geq 2$ years: $100 \mathrm{mg}$ P0 q12hr for 3 days

If cure is not achieved $3 \mathrm{wk}$ after treatment, a second course of treatment is advised

Vermox $\geq 1$ year: $500 \mathrm{mg} \mathrm{PO}$ as a single dose

- Whipworm (Trichuris trichiura)

Emverm $\geq 2$ years: $100 \mathrm{mg}$ P0 q12hr for 3 consecutive days

Vermox $\geq 1$ year: $500 \mathrm{mg}$ PO as a single dose

- Hookworm (Ancylostoma duodenale, Necator americanus)

Emverm, $\geq 2$ years: $100 \mathrm{mg}$ PO q12hr for 3 consecutive days

\section{Levamisole, pyrantel}

These anthelmintics are the nicotinic receptor agonist [9] which causes spastic muscle loss of motion because of which the drawn out enactment of the excitatory nicotinic acetylcholine (nACh) receptors on muscle happens. The method of activity of these receptors has been carefully analyzed at the single channel level on the body wall muscle preparation of Ascaris [10]. So, the pharmacological examination has given proof to the subtypes of nACh receptors [11]. N-type receptors are actuated by nicotine, B-type of nicotinic receptors is initiated by bephenium and a L-type is enacted by levamisole and it is related with levamisole obstruction. Levamisole related compounds additionally delivers spastic loss of motion in egg laying C.elegans. Chronicles from C.elegans body wall muscle utilizing levamisole and nicotine as agonist has given the confirmation that there are muscle subtypes of nACh receptor, and these subtypes have various receptors subunit constituents. The Levamisole receptor subunits are unc-38, unc-29, unc-63 [12,13]. These anthelmintics give the pharmacological instruments to dissect the subtypes and stoichiometries of local nematode nicotinic receptors.

\section{Levamisole}

Pediatric dose:

- $\quad$ Ascariasis

Oral $3 \mathrm{mg} / \mathrm{kg}$ as a single dose

- Ancylostomiasis 
$2.5 \mathrm{mg} / \mathrm{kg}$ as a single dose, repeated after 7 days in severe cases

\section{Pyrantel pamoate}

Pediatric Dose:

- $\quad$ Ascariasis (Roundworm)

>2 years: $11 \mathrm{mg}$ (base)/kg PO x 1 dose; not to exceed $1 \mathrm{~g} /$ dose

- $\quad$ Enterobius (Pinworm)

>2 years: $11 \mathrm{mg}$ (base)/kg P0 q2week x 2 doses; not to exceed $1 \mathrm{~g} /$ dose

- $\quad$ Eosinophilic Enterocolitis (Hookworm; Off-label)

>2 years: $11 \mathrm{mg}$ (base)/kg PO qDay x 3 days; not to exceed 1 $\mathrm{g} /$ dose

- $\quad$ Moniliformis (Off-label)

$11 \mathrm{mg} / \mathrm{kg}$ PO once; may repeat after 14 days

\section{Ivermectin}

Ivermectin is a semisynthetic subsidiary of avermectin which is presented as anthelmintic during the 1980s by Merck contains enormous macrocyclic lactone aged result of the microorganism Streptomyces avermitilis. It is a strong medication and its disclosure prompted the improvement of ivermectin analogs which incorporate moxidectin, milbemycin oxime, doramectin, selamectin abamectin and eprinomectin [14]. Ivermectin causes the loss of motion of pharyngeal and body divider musculature $[15,16]$ It has been appeared to communicate with a scope of ligand-gated particle channels [17] acetylcholine gated chloride channels, GABA gated chloride channels [18-20] histamine gated chloride channels [21] glycine receptors [22]. Nematode glutamate gated chloride channels have high proclivity which as connected with its intense anthelmintic movement. The Merck group was prevailing with regards to communicating the cloning of GluCl $\alpha$ and GluCL $\beta$ particle direct subunits in C.elegans [23] yet the two subunits were communicated either separately or together. GluCl $\alpha$ reacts to small scale molar amount of ivermectin yet not to glutamate while GluCl $\beta$ reacts to glutamate yet not to ivermectin, because connection of Glu$\mathrm{Cl}-\alpha$ and GluCL. $\beta$ yields a channel which reacts to glutamate and it is decidedly however allosterically balanced by nano molar amount of ivermectin [24]. Essentially there are four qualities of C.elegans which are encoded by $\mathrm{GluCl} \alpha$ subunits. Two of which are on the other hand grafted the $\mathrm{GluCl}$ channels the pharyngeal muscle of freaks of avermectin species doesn't react to ivermectin [25]. Ivermectin anthelmintic action against and the pharynx of this species isn't repressed by this medication [26]. The job of $\mathrm{GluCl}$ is intervened by crippled activities of ivermectin is assuming a significant job in the engine sensory system. There is an immuno recoloring job of $\mathrm{GluCl}$ $\alpha 3 \mathrm{An}$ and B engine neurons of the parasitic nematode H.contortus [27]. The job of these GluCl diverts in C.elegans includes the guideline of the span of progress ahead and glutamatergic directed conduct [28]. The disabled activity of ivermectin gets from actuation of $\mathrm{GluCl}$ in the engine sensory system of nematode. The system of ivermectin obstruction has been all around considered in C.elegans as a result of elevated level of opposition is required in change of these species. These qualities further direct film porousness and hole intersections [29].

Pediatric Dose:

- $\quad$ Ascariasis: $150-200 \mathrm{mcg} / \mathrm{kg}$ once only

- $\quad$ Strongyloidiasis: $200 \mathrm{mcg} / \mathrm{kg}$ once only

- $\quad$ Trichuriasis: $200 \mathrm{mcg} / \mathrm{kg}$ OD for 3 days

- $\quad$ Filariasis: $150 \mathrm{mcg} / \mathrm{kg}$ once to be repeated every 6-12 months until the patient becomes symptom free

- $\quad$ Cutaneous larva migrans: $200 \mathrm{mcg} / \mathrm{kg}$ OD for $1-2$ days

- Onchocerciasis: (river blindness): $150 \mathrm{mcg} / \mathrm{kg} /$ once daily

- $\quad$ Loiasis: $150 \mathrm{mcg} / \mathrm{kg}$ once only

- $\quad$ Lice: $200 \mathrm{mcg} / \mathrm{kg}$ once

- Scabies: $200 \mathrm{mcg} / \mathrm{kg}$ once

\section{Diethylcarbamazine}

The clearance of microfilariae of Litomosoides caardii from the coursing blood by diethyl carbamazine and its metabolites in the initial couple of moments after an intravenous portion has been explored. This clearance has been corresponded with the nearness of $14 \mathrm{C}$-named medicate during that time. The medications action is subject to inducible nitric-oxide synthase and cyclooxygenase pathway.

Pediatric Dose:

- For filarial disease

Day 1 mg/kg PO PC

Day 2 1mg/kg PO TID

Day 3 1-2mg/kg PO TID

Day 4-14 6mg/kg/day PO divided TID

\section{Praziquantel}

Builds the penetrability of the layers of schistosome cells towards calcium particles accordingly prompting withdrawal of parasites, bringing about loss of motion in contracted state.

Pediatric Dose:

- $\quad$ Schistosomiasis

$\geq 1$ year: $20 \mathrm{mg} / \mathrm{kg}$ PO TID for 1 day (at intervals of 4-6 hr)

- Indicated for Clonorchiasis and opisthorchiasis caused by liver flukes (Clonorchis sinensis, Opisthorchis viverrini)

$\geq 1$ year: $25 \mathrm{mg} / \mathrm{kg}$ PO TID for 1 day (at intervals of 4-6 hr)

- $\quad$ Cysticercosis (Off-label)

$\geq 1$ year: $50-100 \mathrm{mg} / \mathrm{kg} /$ day PO divided TID for 30 days 
- $\quad$ Tapeworms (Off-label)

$\geq 1$ year: $5-10 \mathrm{mg} / \mathrm{kg}$ as single dose or $25 \mathrm{mg} / \mathrm{kg}$ if caused by Hymenolepis nana

\section{Niclosamide}

Niclosamide works by killing tapeworms on contact. Grown-up worms (however not ova) are quickly executed, apparently because of uncoupling of oxidative phosphorylation or incitement of ATPase action. Niclosamide may fill in as a molluscicide by official to and harming DNA.

\section{Pediatric Dose:}

For oral dosage form (tablets):

- $\quad$ For fish tapeworm or beef tapeworm:

Children - Dose is based on body weight and must be determined by your doctor.

For children weighing 11 to 34 kilograms (kg) (24.2 to 74.8 pounds): 1 gram as a single dose. Treatment may be repeated in seven days if needed.

For children weighing over $34 \mathrm{~kg}$ (74.8 pounds): 1.5 grams as a single dose. Treatment may be repeated in seven days if needed.

- For dwarf tapeworm:

Children - Dose is based on body weight and must be determined by your doctor.

For children weighing 11 to $34 \mathrm{~kg}$ (24.2 to 74.8 pounds): 1 gram on the first day. Then 500 milligrams (mg) once a day for the next six days. Treatment may be repeated in seven to fourteen days if needed.

For children weighing over $34 \mathrm{~kg}$ (74.8 pounds): 1.5 grams on the first day. Then 1 gram once a day for the next six days. Treatment may be repeated in seven to fourteen days if needed.

\section{Research Gap Based on Review}

The absence of cost information and irregularities in the assortment and investigation techniques establishes a significant research gap for helminths contamination control. Itemized and precise expenses or expanding treatment recurrence will be basic to define savvy general wellbeing arrangement. Characterizing the savviest control systems in various settings is of high noteworthiness during this period and new asset duties for helminths contamination control.

\section{Recommended Future Research Agendas}

Future research ought to give new bits of knowledge into the measurable investigation of viability information, which considers in future checking and assessment investigations of enormous scale anthelmintic treatment programs.

\section{Conclusion}

From this review it is concluded that anthelmintic activity of some medications was supported on its resistant activity. Mostly disease caused by Helminthiasis is of chronic exhaust and of severe nature which causes additional morbidity. The Anthelmintics drug treatment should be utilized in chemotherapy programs in those regions wherever clinical support is distributed and wherever medications are very well tolerated in humans. To be concluded a rational drug should be chosen according to the helminthic disease especially in pediatric patients.

\section{Acknowledgement}

None.

\section{Conflict of Interest}

No conflict of interest.

\section{References}

1. Holden-Dye L, Walker RJ (2007) Anthelmintic drugs. Worm Book: The Online Review of C elegans Research Community.

2. Mohammed MS, Mohammed M, Yusuf OS, Joseph OA (2005) Anthelmintic activity of the crude methanol extracts of Xylopia aethiopica against Nippostrongylus brasiliensis in rats. Veterinarski Arhiv 75(6): 487-495.

3. Barar FSK (2000) Essential of Pharmacotherapeutics. pp. 347-453.

4. Anisuzzaman M, Rahman AHMM, Harun-or-Rashid M, Naderuzzaman ATM, Islam AKMR (2007) An Ethnobotanical Study of Madhupur, Tangail. J App Sci Research 3(7): 519-530.

5. Vijayan A, Liju VB, Reena John JV, Parthipan B, Renekac (2007) Traditional remedies of Kani tribes in Kotor reserve forests, Agasthyavanam, Thiruvananthapuram Kerala. Ind J Trad Know 6(4): 589-594.

6. Borgers M, De Nollin S (1975) Ultrastructural changes in Ascaris suum intestine after mebendazole treatment in vivo. J Parasitol 61(1): 110122.

7. Kwa MS, Veenstra JG, Roos MH (1994) Benzimidazole resistance in Haemonchus contortus is correlated with a conserved mutation at amino acid 200 in beta-tubulin isotype. Mol Biochem Parasitol 63(2): 299-303.

8. Kwa MS, Veenstra JG, Van DM, Roos, MH (1995) Beta-tubulin genes from the parasitic nematode Haemonchus contortus modulate drug resistance in Caenorhabditis elegans. J Mol Biol 246(4): 500-510.

9. Aceves J, Erlij D, Martinez-Maranon R (1970) The mechanism of the paralyzing action of tetramisole on Ascaris somatic muscle. Br J Pharmacol 38(3): 602-607.

10. Martin RJ, Verma S, Levandoski M, Clark CL, Qian H, et al. (2005) Drug resistance and neurotransmitter receptors of nematodes: recent studies on the mode of action of levamisole. Parasitology 131: S71-S84.

11. Qian H, Martin RJ, Robertson AP (2006) Pharmacology of N-, L-, and Bsubtypes of nematode $\mathrm{nAChR}$ resolved at the single-channel level in Ascaris suum. FASEB J 20(14): 2606-2608.

12. Culetto E, Baylis HA, Richmond JE, Jones AK, Fleming JT, et al. (2004) The Caenorhabditis elegans gene encodes a levamisole-sensitive nicotinic acetylcholine receptor alpha subunit. J Biol Chem 279(41): 4247642483.

13. Rand JB (2007) Acetylcholine. Worm Book: The Online Review of C elegans Research Community.

14. Haber CL, Heckaman CL, Li GP, Thompson DP, Whaley HA, et al. (1991) Development of a mechanism of action-based screen for anthelmintic 
microbial metabolites with avermectin-like activity and isolation of milbemycin-producing Streptomyces strains. Antimicrob Agents. Chemother 35(9): 1811-1817.

15. Brownlee DJ, Holden-Dye L, Walker RJ (1997) Action of the anthelmintic ivermectin on the pharyngeal muscle of the parasitic nematode, Ascaris suum. Parasitology 115(Pt 5): 553-561.

16. Pemberton DJ, Franks CJ, Walker RJ, Holden DL (2001) Characterization of glutamate-gated chloride channels in the pharynx of wild-type and mutant Caenorhabditis elegans delineates the role of the subunit GluClalpha2 in the function of the native receptor. Mol Pharmacol 59(5): 1037-1043.

17. Krause RM, Buisson B, Bertrand S, Corringer PJ, Galzi JL, et al. (1998) Ivermectin: a positive allosteric effector of the alpha7 neuronal nicotinic acetylcholine receptor. Mol Pharmacol 53(2): 283-294.

18. Bokisch AJ, Walker RJ (1986) The action of Avermectin (MK 936) on identified central neurones from Helix and its interaction with acetylcholine and gamma-aminobutyric acid (GABA) responses. Comp Biochem Physiol C 84(1): 119-125.

19. Holden-DL, Walker RJ (1986) Avermectin and avermectin derivatives are antagonists at the 4-aminobutyr acid (GABA) responses. Comp Biochem Physiol C Comp Pharmacol 84: 119-125.

20. Holden-Dye L, Walker RJ (1990) Avermectin and avermectin derivatives are antagonists at the 4-amino butyricacid (GABA) receptor on the somatic muscle cells of Ascaris; is the site of anthelmintic action. Parasitology 101(Pt 2): 265-271.

21.Zheng Y, Hirschberg B, Yuan J, Wang AP, Hunt DC, et al. (2002) Identification of two novel Drosophila melanogaster histamine-gated chloride channel subunits expressed in the eye. J Biol Chem 277(3): 2000-2005.
22. Shan, Q, Haddrill JL, Lynch JW (2001) Ivermectin, an unconventional agonist of the glycine receptor chloride channel. J Biol Chem 276(16): 12556-12564.

23. Cully DF, Vassilatis DK, Liu KK, Paress PS, Van der Ploeg LH, et al. (1994) Cloning of an avermectin-sensitive glutamate-gated chloride channel from Caenorhabditis elegans. Nature 371(6499): 707-711.

24. Yates DM, Portillo V, Wolstenholme AJ (2003) The avermectin receptors of Haemonchus contortus and Caenorhabditis elegans. Int J Parasitol 33(11): 1183-1193.

25. Dent JA, Davis MW, Avery L (1997) avr-15 Encodes a chloride channel subunit that mediates inhibitory glutamatergic neurotransmission and ivermectin sensitivity in Caenorhabditis elegans. EMBO J 16(19): 58675879 .

26. Holden DL, Walker RJ (2006) Actions of glutamate and ivermectin on the pharyngeal muscle of Ascaridia galli: a comparative study with Caenorhabditis elegans. Int J Parasitol 36(4): 395-402.

27. Portillo V, Jagannathan S, Wolstenholme AJ (2003) Distribution of glutamate-gated chloride channel subunits in the parasitic nematode Haemonchus contortus. J Comp Neurol 462(2): 213-222.

28. Brockie PJ, Maricq AV (2006) Ionotropic glutamate receptors: genetics, behavior and electrophysiology, Worm Book: The Online Review of C elegans Research Community.

29. Dent JA, Smith MM, Vassilatis DK, Avery L (2000) The genetics of ivermectin resistance in Caenorhabditis elegans. Proc Nat Acad Sci USA 97(6): 2674-2679. 